\title{
Re-examining Australia's hidden genocide: the removal of Aboriginal children in Australia as an act of cultural genocide
}

\author{
Emily Mays
}

University of Technology Sydney, Faculty of Arts and Social Sciences, PO Box 123, Ultimo NSW 2007, Australia. emily.mays@student.uts.edu.au

\begin{abstract}
The 1997 Bringing Them Home Inquiry (BTHI) sparked a significant shift in public understanding of the Stolen Generations. While substantial evidence incriminated the Australian government with acts of genocide, the allegations were subdued by the division around the circumstances in which Aboriginal children were removed. This essay analyses political discourse before and after the BTHI, while offering a contemporary understanding of genocide.
\end{abstract}

Key words: Stolen Generations; genocide; Aboriginal history; history wars; assimilation policy

Since the culmination of the 20th century, a once-silenced history of Aboriginal children being separated from their parents has become so widely dispersed that the Stolen Generations narrative is now central to the Australian political landscape and historical consciousness. Following the release of the Bringing Them Home Inquiry (BTHI) in 1997, there has been a significant shift in understanding the history of the Stolen Generations. The report made several recommendations to the government, many of which were contentious with the conservative Howard government, who sought to discredit the inquiry entirely. The BTHI was highly debated by the Australian government in two-fold; by claiming the historical evidence of the report was fabricated and ergo, disproving its presumption of genocide. The legitimacy of the report has also been interrogated by historians who speculate an absence of inquiry into diverse experiences of separation, and by doing so, the BTHI has created a Stolen Generations narrative that transcends and devalues divergent narratives. The silencing of these 'smaller truths' was an erroneous oversight, not only for Indigenous people whose experiences of separation became suppressed, but also granted certain groups 
justification to dismiss the report and Aboriginal child removal entirely. While substantial evidence incriminated the Australian government with acts of genocide, the allegations were subdued by an overall division regarding the circumstances of the Stolen Generations during the 20th century. This essay will address the above issues before offering a contemporary understanding of genocide that is more appropriately applicable to the removal of Indigenous children in Australia.

The formation of 'Link-up' in the 1980's by Peter Read and Coral Edwards, an Aboriginal woman who was removed from her family when she was five years old, played a crucial role in emerging discourse around the removal of Indigenous children from their families throughout the 20th century. The organisation worked towards reconnecting individuals with their Aboriginal families and assisting with cultural re-integration where desired. A pivotal point came when Edwards addressed the National Aboriginal Conference of 1983, where hundreds of attendees were astounded to learn the removal of Aboriginal children was a government policy; illustrating a much larger issue of historical misunderstanding, even within Aboriginal communities (Attwood 2003). Attwood contends that had Aboriginal people understood there was a Government policy in place, they would have recognised the manifestation of child removal in their own communities and nationwide (Attwood 2003). In the same vein, these silent processes actively shaped what both Aboriginal and nonAboriginal people perceived as truth. The work of Edwards and Read revealed these hidden histories and created a massive shift in the historical understanding of state and federal policies, paving the way for the Bringing Them Home Inquiry. The two-year-long national inquiry made several claims including that forcible removals had occurred to as many as one in three between 1910 and 1970; removals had occurred from the beginning of European colonisation and throughout Australia; and that the main objective of removals were to prevent further production of 'Aboriginality' (Attwood 2003). Along with these claims came several recommendations for the Australian Government, including recognition of genocide.

The findings of the report ignited the Stolen Generations narrative, which has become a symbol of the destructive consequences of colonisation in Australia. However, this 'new' history was disputed by the Howard government and other conservative bodies at the time, who delayed the release of the report and promptly rejected its recommendations (Goodall 2002). This highly politicized approach attacked the historical accuracy of the report by denying out-of-hand there was a generation of stolen Indigenous children and defended that any separation was lawful and of benevolent intent (Attwood 2003). While significant evidence demonstrated there was in fact a generation of stolen children, the inquiry did fail in a number of other ways. Firstly, the Stolen Generations narrative framed all separations as 'forced removals' from parents or kin. Read remarks on the diversity of lived experiences, arguing that the range of these experiences, such as successful white adoptions and removal on the insistence of a non-Aboriginal guardian, were not represented in the report (Read 2002). Therefore, the BTHI pigeonholed the diverse experiences of Aboriginal people in an attempt to exemplify institutionalized violence and genocidal intent. Secondly, the report exaggerated the number and rate in which children were removed from their families. Seeing as no investigation was ever conducted to establish an estimated figure, and likely never will 
be conducted due to the absence of data, the report made claims that could not be verified (Attwood 2003). These two missteps not only undermined ongoing dispossession of Aboriginal people and rejected the diversity of experiences of the Stolen Generations, but also aided the propagation of distrust in this 'new' history. Conversely, the BTHI presented an accurate 'big truth' of violent dispossession, rather than a collection of 'smaller truths' that may have convoluted public understanding of what was indeed a generation of stolen Aboriginal children (Read 2002). In fact, Read asserts that admission of these 'smaller truths', such as child removal by a non-Aboriginal guardian as opposed to the government, were argued by Prime Minister John Howard to have weakened the historical argument about the Stolen Generations entirely (Read 2002). With this being said, highlighting a 'big truth' should not necessarily subvert the legitimacy of the Stolen Generation's narrative or the extent to which genocide is applicable to child removal policies in Australia during the 20th century. Nevertheless, the question of genocide is still undetermined despite its validity in the Australian historical landscape, revealing the nation's narrow understanding of genocide.

Following the atrocities of the Holocaust, the United Nations Convention on the Prevention and Punishment of Genocide outlined the crime of genocide on a global scale. Polish lawyer, Raphael Lemkin, was first to coin the concept of genocide as 'the destruction of a nation or ethnic group... not only through mass killings, but also through a coordinated plan of different actions aiming at the destruction of essential foundations of the life of a national group, with the aim of annihilating the groups themselves' (Kunz 1949, p. 738). In line with this definition and Article II of the Australian Genocide Convention Act, the removal of Aboriginal children from their parents were 'acts committed with the intent to destroy, in whole or in part, a national, ethical, racial or religious group' through '(e) forcibly transferring children of the group to another group' (Genocide Convention Act 1949). However, the Genocide Convention outlines a narrow understanding of genocide, establishing a sense of ambiguity around many historical events that may or may not be categorized as genocidal. A narrow comprehension confines genocide to the act of killing and physical annihilation, while broader understandings acknowledge that groups of people and their cultural histories can be eliminated in a range of ways. Since the UN Genocide Convention was established in 1948, Australia adopted a narrow viewpoint, evident through the Government's refusal to recognise child removal as a form of genocide. However, this stance is unsurprising when considering the events leading up to the formation of the UN Genocide Convention. Moreover, certain genocides, such as the Holocaust in Europe which is notable for its unruly violence, make the rest of the world 'civilized' and humane by contrast (Hinton, La Pointe \& Irvin-Erickson 2014).

Synonymous with colonialism, genocide is closely intertwined with modernity and is manifested within the 'civilized' world. While Australia voluntarily became a party to the Genocide Convention, the government policy that allowed the removal of Aboriginal children ceased almost three decades later. In addition to this, the Australian Commonwealth Government only legislated to make genocide a crime in 2002, making it appropriate to speculate whether the delay was a matter intentional passivity on the basis that the Australian Government has committed acts of genocide against Indigenous people (Scott 2004). In the 
same vein, even if Australia's narrow understanding of genocide, limited to the physical annihilation of groups, prevented acknowledgment of the Stolen Generations, in theory it should have acknowledged the atrocities in Tasmania during the 19th century. The Aboriginal population of Tasmania was reduced from an estimated 10,000 in 1834 to 1,907 by 1853, a decline of 80 per cent in two decades (Breen 2011). Yet, these events are still to this day denied by Australia to constitute a genocide. These hidden genocides have become a global phenomenon, covered up by governments that derive their political legitimacy from claiming to uphold human rights (Hinton, La Pointe \& Irvin-Erickson 2014). Australia is a prime example of a 'civilized' nation that cannot admit it was founded through acts of genocide, while simultaneously condemning other forms of human destruction. It can be argued that contemporary society is convinced that genocide is a circumstance of the distant past, with the assertion its legitimacy is only affirmed when dealing with the mass killing of groups by 'savages'. However, the act of genocide has adapted as the social and political landscape has changed, shifting from physical violence to 'lawful' policies of child removal and assimilation; Australian policies that constitute a cultural genocide.

Cultural genocide is defined as the intentional destructive targeting of a group's culture as a means to destroy or significantly weaken them in the process (Davidson 2012). When discussing cultural genocide, it is critical to first emphasize the importance of local knowledge and its capacity to form an individual's identity, connection to culture and an overall sense of belonging. Davidson asserts that our immediate environments are important arenas to all of us, whereby we interact and share local knowledge of history and culture (Davidson 2012). As an example, travelling abroad into a foreign locale does not deviate our existing and secure sense of identity, but rather one would employ their local knowledge to navigate the new environment. However, a common plight of Aboriginal children removed from their families and subsequently assimilated into foreign environments was an absence of a fundamental sense of identity (Attwood 2003). The removal of children from their local environments has sociological implications on childhood development, which typically constitute the years of considerable identity growth. Therefore, if natural localness is fundamental to individual identity and cultural knowledge, especially during childhood, then a destruction of this natural localness is a viable tactic to eliminate a group's culture (Hinton, La Pointe \& Irvin-Erickson 2014). The Australian government's attempt to solve the 'great problem' of 'Aboriginality' was the absorption of children into the non-Aboriginal way of life and ultimate isolation from their Aboriginal communities. On the other hand, targeting and removing Aboriginal children can also be viewed as an attempt at social engineering, by employing a strategy of reproductive control to 'breed out the colour' (Van Krieken 2004). In doing so, the unique cultural values and ethnic identities of Aboriginal children would dissolve, along with over 60,000 years of Aboriginal history. However, similar to Robert Donaldson who took a deep interest in the 'welfare' of Aboriginal people by means of isolating them from their communities (Read 2002), Prime Minister John Howard also asserted that any child removal that had occurred was welfare driven (Van Krieken 2004). Comparable to many hidden genocides globally, perpetrators come to see their acts as a form of compassion toward the victims (Hinton, La Pointe \& Irvin-Erickson 2014). This assumption defines welfare and genocide as mutually exclusive terms; claiming one naturally 
denies the validity of the other. However, a broader understanding of genocide would consider perceived 'welfare' and genocide to be compatible with one another; that the pursuit of 'welfare' can simultaneously be comprehendible as 'genocidal' (Van Krieken 2004). Yet, the UN Genocide Convention fails to identify these contemporary practices as genocidal. Specifically, this comprehension of genocide fails to define past and current colonial practices as genocidal and as such, nations are not held accountable for such events.

Since the mid-1980's, specifically following the release of the Bringing Them Home Inquiry, certain groups have been unwilling to accept a 'new' Australian history of truths about racism, dispossession and destruction of Aboriginal people. Despite the BTHI's failure to represent the diversity of experiences of the Stolen Generations and the exaggeration of the number and rate in which children were removed, the report has allowed for a significant shift in the historical consciousness of Australia, for both Aboriginal and non-Aboriginal people. The report's most contended finding claimed that the main purpose of child removal was to prevent the reproduction of 'Aboriginality' and as such, amounted to genocide (Attwood 2003). Despite these findings, the removal of Aboriginal children in Australia during the 20th century is yet to be investigated as an act of genocide. Arguably, this reveals Australia's narrow understanding of genocide, whereby its validity is determined by physical elimination of a group of people. The removal of Aboriginal children, however, is not simply a 'mistake' for which apologies must be issued, but a construct deeply rooted in colonial social and political thought, with intergenerational implications for Aboriginal people across Australia (Van Krieken 2004). Likewise, the UN Genocide Convention has also failed to hold nations accountable within this broader framework. Hidden genocides have become a global circumstance, in which affluent nations that derive their political legitimacy from their adoption of human rights, are eliminating groups of people by more subtle means. The removal of Aboriginal children in Australia has significantly reduced shared cultural and historical knowledge of and among generations of Aboriginal people, through desocializing vulnerable children from their Aboriginal communities and assimilating them into nonAboriginal society. Moreover, the removal of Aboriginal children was a government policy up until the 1970's and regardless of its 'benevolent' intent, can and should be regarded as a cultural genocide. It is crucial that the UN Genocide Convention is adapted to contemporary affairs for it to be a reliable guide for a useful understanding of genocide. Until such reevaluations take place, nations like Australia will never recognise broader acts of genocide and ergo, fail to take meaningful action towards reconciliation. Not only does this continue to have ongoing implications for the dispossession of Aboriginal people and their cultural knowledge, but prevention of similar government policies are not protected by international laws. 


\section{References:}

Attwood, B. (2003). Telling Stories : Indigenous History and Memory in Australia and New Zealand. Crows Nest, N.S.W.: Allen \& Unwin, pp.183-212.

http://web.a.ebscohost.com.ezproxy.lib.uts.edu.au/ehost/detail/detail?vid=0\&sid=2710b35c68db-43a3-b8a4-8ec91eca9d75\%40sdc-vsessmgr03\&bdata=JnNpdGU9ZWhvc3QtbGl2ZQ\%3d\%3d

Breen, S. (2011). Extermination, Extinction, Genocide. Philadelphia, PA: University of Pennsylvania Press.

https://www.academia.edu/2474043/Extermination_Extinction_Genocide_British_Colonialis m_and_Tasmanian_Aborigines

Davidson, L. (2012). Cultural genocide. New Brunswick, N.J.: Rutgers University Press. https://ebookcentral.proquest.com/lib/uts/detail.action?docID=871841

Genocide Convention Act 1949 (Cth).

https://www.legislation.gov.au/Details/C1949A00027

Goodall, H. (2002). Too early yet or not soon enough? Reflections on sharing histories as process. Australian Historical Studies, 33(118), pp.7-24.

https://www.tandfonline.com/doi/abs/10.1080/10314610208596176? journalCode=rahs20

Hinton, A., La Pointe, T. and Irvin-Erickson, D. (2014). Hidden Genocides: Power, Knowledge, Memory. New Brunswick, New Jersey: Rutgers University Press. https://ebookcentral.proquest.com/lib/uts/detail.action?docID=1573368

Kunz, J. (1949). The United Nations Convention on Genocide. The American Journal of International Law, 43(4), p.738.

https://www.jstor.org/stable/2193262?seq=1\#page_scan_tab_contents

Read, P. (2002). Clio or Janus? Historians and the stolen generations. Australian Historical Studies, 33(118), pp.54-60.

https://www.tandfonline.com/doi/abs/10.1080/10314610208596179

Scott, S. (2004). Why wasn't genocide a crime in Australia? Accounting for the half century delay in Australia implementing the Genocide Convention. Australian Journal of Human Rights, 10(1), pp.159-178.

https://www.tandfonline.com/doi/abs/10.1080/1323238X.2004.11910775

Van Krieken, R. (2004). Rethinking Cultural Genocide: Aboriginal Child Removal and Settler-Colonial State Formation. Oceania, 75(2), pp.125-151.

https://onlinelibrary.wiley.com/doi/abs/10.1002/j.1834-4461.2004.tb02873.x 